\title{
FOGO MORTO E O CICLO DA CANA: POR UMA REINTEGRAÇÃO
}

Taciana Alves de Faria*

RESUMO:

Este trabalho tem os objetivos de mostrar a integração de Fogo morto ao ciclo da cana-de-açucar, de José Lins do Rego, já que a recepção crítica do romance o considera um livro à parte, e de se opor ao reconhecimento feito pela crítica de uma possivel atitude nostálgica que o romancista teria em suas primeiras publicações.

PALAVRAS-CHAVE: literatura brasileira, regionalismo, José Lins do Rego, ciclo da cana-de-açúcar, Fogo morto.

Publicado em 1943, Fogo morto volta ao mundo dos engenhos, retomando o ciclo da cana-de-açúcar que o próprio José Lins do Rego afirmara ter encerrado com Usina, publicação de 1936. Desde o primeiro momento, porém, Fogo morto recebeu posição de destaque dentro da obra, postura ainda hoje predominante na crítica literária brasileira e abertamente assumida, por exemplo, por Afrânio Coutinho, que afirma ser Fogo morto "um romance que se destaca da mediania das obras do autor, constituindo, na verdade, a sua única produção excelente." ${ }^{1}$

0 estudo da recepção crítica do chamado ciclo da cana-de-açúcar revela o procedimento que acompanha o destaque dado ao romance, que consistiu, basicamente, em como que "retirá-10" do conjunto do qual faz parte, mas que parece, contraditoriamente, fechar com chave de ouro.

De fato, parece estar consolidada, na crítica literária brasileira, a idéia de que, em Fogo morto, encontramos um escritor muito mais consciente do que nos primeiros romances, que estariam marcados pela força do relato memorialista.

* Mestre em Letras: Estudos Literários (Área de concentração: Teoria da Literatura), 2002. 


\section{EMTESE}

Belo Horizonte, v. 7, p. I-I I0, dez. 2003

Assim, ao lado da idéia de que Fogo morto seria uma espécie de síntese dos primeiros romances, e estes meros exercícios ou rascunhos da obra-prima, pode-se reconhecer a tendência em se caracterizar as produções literárias de José Lins como se passassem por uma linha evolutiva, de ascensão, o que determinaria um aprimoramento estético e temático.

Esse fato, por si só, reservaria, a Fogo morto, uma posição vantajosa, em detrimento das anteriores. Fogo morto seria, desse modo, uma espécie de "pico literário", de "cume criativo" de uma proposta iniciada em 1932, com o primeiro romance de José Lins. Considera-se que os primeiros livros estariam muito próximos de uma autobiografia, o que comprometeria o caráter ficcional das obras. Com o tempo, o romancista ter-se-ia libertado, por assim dizer, dos laços que o prendiam ao passado, caminhando em sentido da "criação pura", da total invenção.

Tais considerações estabelecem uma divisão entre os romances de José Lins: as primeiras publicações - Menino de engenho, Doidinho e Bangüê - seriam memorialistas ou autobiográficas, enquanto as obras posteriores - 0 moleque Ricardo, Usina e Fogo morto - conseguiriam um pouco mais de "autonomia", encontrando-se, assim, em um estágio superior, do qual Fogo morto seria o maior exemplo.

Pode-se dizer que críticas dessa natureza realizam uma espécie de classificação que distingue memória e criação artística, concebendo a primeira como um "estágio primário" de desenvolvimento literário, espécie de etapa primeira, cujas produções seriam reminiscências de infância e adolescência, lembranças transpostas para o âmbito da literatura.

De acordo com esse ponto de vista, autores como José Lins do Rego fariam antes um trabalho de "recriação" do que propriamente de "criação", já que suas obras seriam consideradas mera representação de uma realidade, associadas a um possivel trabalho artístico com a forma.

Levando em consideração o ciclo da cana, por nós enfocado, Aderaldo Castel10, por exemplo, salienta que José Lins teria realizado um trabalho um tanto restrito, no que diz respeito à criação artística ou temática, uma vez que considera os romances como "produtos de experiência vivida". Segundo o crítico, pelo fato de José Lins ter passado sua infância e parte da adolescência em um engenho, integrado 
ao universo rural, suas obras, ambientadas nesse contexto, revelariam um menor trabalho de ficcionalização, pois caminhariam muito próximas a fatos por ele vivenciados. Afirma, desse modo, que, sobretudo no ciclo da cana-de-açúcar, a criação seria inerente à memória, sendo esta reguladora daquela; e, como tal, haveria uma postura muito mais instintiva do que criativa, como se tivesse havido abdicação de todo um trabalho mental, subjetivo e pessoal de invenção e criação por parte do autor, como se este fosse mero instrumento de trabalho mecânico, cujo papel seria simplesmente deixar vir à tona as lembranças de um passado.

Acreditamos que tais posições, entretanto, revelam-se restritivas e excludentes a respeito da obra de José Lins, na medida em que consideram textos cuja fonte tenha sido basicamente a memória como "menores". Ora, a opção por um tom mais pessoal de narrar, de contar histórias, não implica, necessariamente, que os romances sejam simples apreensão ou absorção do mundo; ao contrário, trata-se também de uma forma de percebê-10, criá-10, inventá-10.

Especificamente no caso de José Lins do Rego, as memórias serviram-1he de inspiração, de elemento deflagrador de todo potencial acumulado através de suas experiências pessoais, de tudo o que viu, e também do que não viu. 0 próprio romancista admite que sempre buscou no passado inspiração para seus romances, à terra esteve ligado, dela sugou a força de que precisava para criar e para fazer "viver criaturas".

A oposição memória / criação, portanto, não parece ser pertinente. Não há por que antagonizá-las, criando-se um paradoxo, pois ambas podem caminhar lado a 1ado. A criação pode ter como fonte de inspiração a memória, sem que, com isso, seja considerada "menos literária".

Segundo Mário de Andrade, toda criação deriva de alguma reminiscência, pois não existe "invenção pura". As lembranças constituem o cerne, a base para as produções, já que estas não podem se libertar das primeiras. Não há como negar a memória ou fugir dela, na busca de um ideal, algo "totalmente inventivo", pois é como se fossem os dois processos faces da mesma moeda, um atuando e influenciando o outro. A partir dessa perspectiva, podemos, com Mário de Andrade, enfocar a polêmica não sob um ponto de vista excludente, mas analitico. Partindo-se do 


\section{EMTESE}

Belo Horizonte, v. 7, p. I-I I0, dez. 2003

pressuposto de que as invenções não se dão "do nada", pode-se reconsiderar a divisão feita no conjunto que compõe o ciclo da cana-de-açúcar, de José Lins do Rego.

Não há por que, nesse caso, considerar Fogo morto destacado dos demais romances, pois o livro de 1943 foi tão inspirado no universo rural, nos engenhos de cana, quanto qualquer um dos outros cinco romances, tendo, como seus antecessores, traços de realidade, acrescidos de elementos subjetivos, de criação.

Subjacente a essa discussão teórica sobre as relações entre ficção e vida, pode-se, entretanto, reconhecer uma discussão político-ideológica, que também se baseia em um destaque de Fogo morto em função dos demais romances do ciclo. Considera-se que o caráter crítico do livro de 1943 dever-se-ia à tomada, no romance, de uma postura política mais explícita.

Desse modo, aos cinco primeiros romances do ciclo é negligenciado, ou até negado, que assumam um caráter crítico, sendo percebidos como uma espécie de "fuga" do presente e "refúgio" no passado. Fogo morto seria o único a "escapar" seja de um suposto saudosismo puro e simples, de uma nostalgia, seja de uma postura descompromissada, acrítica, para atingir uma visão problematizada, ou supostamente revolucionária, do universo nordestino.

Para Eduardo Coutinho, esse caráter crítico de Fogo morto estaria vinculado ao tipo de narrador utilizado, uma terceira pessoa que denuncia as ideologias presentes no texto, encaminhando os discursos das personagens.

Alia-se, assim, ao argumento ideológico, o argumento estético, fundado na afirmação de que Fogo morto contaria com maior "elaboração estética"2 e rigor de construção. Segundo Afrânio Coutinho, a "tripartição interna" do romance dá-1he um caráter de renovação a cada parte que se inicia, como se houvesse três recomeços, impedindo uma queda de interesse do leitor, devido a um "enfraquecimento da narrativa"3, como aconteceria, segundo ele, nos outros romances de José Lins. Diferente do que ocorre em Menino de engenho, Doidinho e Bangüê, em que os acontecimentos são contados de forma linear e descritiva, seguindo a ordem de lembranças do narrador / autor, em Fogo morto constata-se uma maior dinamicidade, que, de acordo com Afrânio Coutinho, é proporcionada pela "dialogação constante associada ao uso da 
linguagem coloquial"4, fatores decisivos, na opinião do crítico, e que colocariam Fogo morto em uma "posição sem paralelo, entre as outras obras do autor"5.

A questão, portanto, está diretamente ligada, a nosso ver, à idéia de "parcialidade". Conforme Eduardo Coutinho, Fogo morto não possuiria uma voz que viesse a se sobrepor às demais - como ocorreria no caso dos primeiros romances, narrados em primeira pessoa e associados, pela crítica, ao memorialismo.

A argumentação, entretanto, é questionável, uma vez que o caráter dialógico de um texto não se define, a priori, pelo tipo de narrador existente, mas sim pela multiplicidade de pontos de vista acerca do mundo. Pode haver dialogismo em narrativas de primeira pessoa, assim como uma de terceira pode ser monológica.

0 objetivo aqui não é, entretanto, negar o caráter questionador e crítico de Fogo morto. Trata-se de indicar a necessidade de "reintegração" do romance ao conjunto a que pertence, realizando um estudo dessas obras como integrantes de um todo. Nesta perspectiva, cabe perguntar se a própria visão de mundo construída em Fogo morto não deveria ser buscada justamente nas relações que mantém com os outros romances. E ainda, se, constituindo-se como uma espécie de "síntese", ou de leitura do ciclo que vem fechar, Fogo morto, restituído ao ciclo a que pertence, estenderia essa visão crítica aos demais romances.

Nossa análise toma como fios condutores a interdependência do enredo dos romances e um tipo de personagem que pode também manifestar essa integração: aquelas que possuem a capacidade de transitar de um romance a outro, sendo dotadas, assim, de uma espécie de "transcendência", sendo elas José Paulino, Carlos de Melo, Juca e Lula de Holanda, como representantes da aristocracia rural; José Amaro e Ricardo, simbolizando o homem livre e pobre, destituído de direitos, seja no campo ou na cidade.

A idéia de uma "reintegração" de Fogo morto ao conjunto ao qual pertence justifica-se quando se percebe o quanto se torna enriquecedora e muito mais ampla uma leitura que tenha o ciclo como base e não apenas um ou outro romance isoladamente.

Acreditamos que José Lins tenha produzido todo um conjunto crítico de romances sobre a decadência - seja de estruturas predominantes em um Nordeste 


\section{EMTESE}

Belo Horizonte, v. 7, p. I-I I 0, dez. 2003

agrário, seja em relação ao homem e ao contexto social urbano - que abrange todos os níveis, todas as esferas: no campo, através da figura falida de usineiros ou de fracassados senhores de engenho; e na cidade, por meio da miséria e da degradação humana que atinge os trabalhadores. Percebemos a existência não somente do tom da denúncia social, característica marcante entre os romances da década de trinta, mas, sobretudo, da falta de perspectivas para a solução desses problemas.

Desse modo, uma interpretação que tivesse como parâmetro apenas Fogo morto, por exemplo, não seria capaz de fornecer a perspectiva cética, o olhar pessimista e descrente de José Lins do Rego em relação à realidade agrária nordestina que abarca fins do século dezenove e início do século vinte. Quando se atenta para a personagem José Paulino, símbolo da modernização e do progresso, contrastando com a ruína de Lula, a leitura isolada de Fogo morto poderia sugerir a ilusão de luz no fim do túnel, mas o que se percebe, ao final de todo o ciclo, é a ausência completa de perspectivas, seja no campo ou na cidade, no passado ou no futuro. Ao escrever o livro de 1943, José Lins já havia traçado todo um cenário decadente para as terras que um dia pertenceram a José Paulino. Desse modo, a modernização incorporada pelo velho patriarca e por seu engenho, aparentemente apontada como alternativa ao franco declínio de Lula e de todas as demais personagens do romance que percorrem uma trajetória decadente, anula-se, esvazia-se, quando se retoma o ciclo. Nas obras publicadas anteriormente já havia se dado a morte do coronel, a venda do Santa Rosa e sua transformação em usina, a falência da Bom Jesus.

Portanto, como se vê, a idéia do "conjunto", das obras constituírem um todo se manteve como prerrogativa ao longo do trabalho, mas também tivemos como intuito não promover o encerramento do tema proposto, e sim realizar um movimento de expansão, de reavaliação das posições críticas a respeito do ciclo da cana e do próprio autor, no que se refere à contextualização no Regionalismo Nordestino e nas relações com o Modernismo. 
NOTAS:

1. Coutinho, Afrânio. A Literatura no Brasil, v. 5, p. 354.

2. ALMEIDA, José Maurício Gomes de. A tradição regionalista no romance brasileiro (1857 1945), p. 196.

3. COUTINHO, Afrânio. A Literatura no Brasil, v. 5, p. 354.

4. Ibidem, p. 357.

5. Ibidem, p.357.

RÉSUMÉ :

Ce travail a les objectifs de mettre en évidence l'intégration de Fogo morto au cicle de la canne à sucre, de José Lins do Rego, parce que la réception critique du roman le considere un livre à part; et de questionner une possible attitude nostalgique que le romancier aurait maintennue dans ses premières publications, signaleé par la critique.

MOTS-CLÉS: littérature brésilienne, régionalisme, José Lins do Rego, cicle de la canne à sucre, Fogo morto.

ALMEIDA, José Maurício Gomes de. A tradição regional ista no romance brasileiro (1857 - 1945). Rio de Janeiro: Achiamé, 1981.

COUTINHO, Afrânio. 0 Regionalismo na Ficção. In: (Dir.). A Literatura no Brasil. Rio de Janeiro: Editorial Sul Americana, 1969. p. 219-224.

COUTINHO, Eduardo F.; CASTRO, Ângela Bezerra de (Org.). José Lins do Rego. João Pessoa: FUNESC; Rio de Janeiro: Civilização Brasileira, 1991. 